\title{
Contribution of organic acids to the pool of surface active substances in model and marine samples using o-nitrophenol as an electrochemical probe
}

\author{
B. Gašparović, B. Ćosović, V. Vojvodić \\ Ruđer Bošković Institute, Center for Marine and Environmental Research, HR-10001 Zagreb, \\ Croatia
}

\begin{abstract}
Voltammetric prepeak height of the of o-nitrophenol (ONP) probe is very sensitive to the presence of acidic organic matter adsorbed on the mercury electrode. ONP prepeak height increases with increasing acidity of organic substances, depending also on their concentrations in solution and on adsorption time. For a better interpretation of real marine samples, adsorption behaviour was studied of a few model substances which may contribute to the acidity of the sample. Also, in phytoplankton monoculture media of diatom Phaeodactilum tricornutum, it was found that major acidic organic substances originated from hydrophilic fraction while acidity of organic substances excreted by microflagelate Emiliana huxleyi was mostly ascribed to hydrophobic acid organic substances. Seawater samples from two stations in the northern Adriatic sea were investigated monthly during an one year period. The highest acidity values of the present organics were noticed during the winter period, corresponding to the dominant humic type organic material, while the obtained acidity values were lower in periods of higher phytoplankton activities. In two fractionated northern Adriatic seawater samples, the results obtained with the ONP probe demonstrated well how the composition of organic matter is influenced by dominant phytoplankton populations .
\end{abstract}

Keywords - Organic acids, o-Nitrophenol, Fractions, Surface active organic substances, Diatoms, Microflagelates, Northern Adriatic, Voltammetry

Short title - Organic acids in marine samples 


\section{INTRODUCTION}

Marine organic matter is a very complex mixture, participating in many reactions both with organic and with inorganic species. A very important part of organic matter in the seawater are organic acids. Recently, there has been a growing interest in elucidating the role of organic acids in biogeochemical processes in natural waters (McKnight et al., 1990).

The total pool of dissolved organic acids is made up of labile, mostly low molecular weight substances, and recalcitrant species. Recalcitrant substances are the greater fraction of higher molecular weight acids, composed mainly of humic substances. Another large portion consists of more hydrophilic organic acids which may have similar properties to fulvic acids.

It was found that low molecular weight substances dominate the components of the mixture which comprises fulvic acid (Novotny and Rice, 1995) whose molecular weights are in the range 1000 2000, while molecular weight of humic acids appears to be 2000-10000 and more. Carboxylic groups are more important in fulvic than in humic acids (Green et al., 1992).

Marine humic substances are the most stable products of organic matter decomposition in nature. They are an unavoidable component of the ecosystem, important reservoir of biogenic elements, and they make the main fraction of dissolved organic matter in natural waters (Skopinstev, 1981; Romankevich, 1984; Aiken et al., 1985; Buffle, 1988). Marine humic substances have a great influence on physical, chemical, and biological processes in the sea environment due to their structure and physico-chemical properties. Complexation reactions with metals are caused by the presence of carboxylic and other oxygen containing functional groups in the molecule, while the binding of organic micropollutants is mainly determined by hydrophobic interactions. Humic substances can be electron mediators in redox processes.

Polysaccharides with acidic properties can be found in the water column as a result of algal extracellular excretion or autolysis. Polysaccharides as well as proteins and lipids are labile in seawater and are promptly decomposed. Interactions between the products of decomposition of marine macromolecules lead to the formation of natural geobiopolymers, in which carbohydrate carbonyl units were found (Romankevich, 1984). It was found that carbohydrate units are more abundant in fulvic acids than in humic acids (Yumaoka, 1983).

Melanoidins are polymers similar to natural humic substances obtained by dehydration and condensation of sugars and amino acids (Hedges, 1978). They are known as kerogen precursors and geochemical lipid sinks (Larter and Douglas, 1980). 
Recently, an electrochemical method was developed which can be used for rough characterization of the type and concentrations of organic matter on the basis of electrochemical properties of onitrophenol (ONP) as a probe (Gašparović and Ćosović, 1994). Using this method, the acidity of the surface active organic matter in the sample can be roughly estimated by following the changes of the ONP prepeak height (Gašparović and Ćosović, 1995). The method was improved by fractionation of organic matter in seawater samples into fractions of different hydrophobicity using the XAD-8 resin (Gašparović et al., 1997). Experiments with different model substances have shown that fatty acids go to the hydrophobic basic and neutral fraction, humic and fulvic acids to the hydrophobic acid fraction, neutral polysaccharides to the hydrophilic fraction, while acidic polysaccharides are distributed between hydrophilic ( 80\%) and hydrophobic acid ( 20\%) fractions (Vojvodić et al., 1994; Gašparović et al., 1997).

In this work we attempted to evaluate the type and origin of surface active organic acids in natural seawater samples and their seasonal variations. Comparison is made with previous results obtained by using very different model substances, from a simple unsaturated fatty acid to more complex humic and fulvic acids, melanoidins, and acidic polysaccharides. In two phytoplankton culture media, we tried to determine which fractions, hydrophilic or hydrophobic, are responsible for the acidity of excreted organic substances. Seawater samples used in this work were collected in the northern Adriatic Sea. Some samples were fractionated before analysis on the XAD-8 resin. In these samples, the results are discussed with regard to the contribution of organic acids to particular fractions.

\section{EXPERIMENTAL}

Phase sensitive ac voltammetric measurements were performed by the EDT-ECP 110 Modular Research Polarograph (London, England). All experiments were performed in a three electrode system with hanging mercury drop electrode (HMDE) by Metrohm (Switzerland). $\mathrm{Ag} / \mathrm{AgCl}$ electrode was used as the reference electrode and a platinum wire as the auxiliary electrode. ONP $\left(10^{-4} \mathrm{M}\right)$ was added into the model solution or to the marine sample just before voltammetric measurement. Model solutions contained $0.55 \mathrm{M} \mathrm{NaCl}$ and $2 \times 10^{-3} \mathrm{M} \mathrm{NaHCO}_{3}$, at $\mathrm{pH} 8.4$, simulating seawater conditions. Organic matter was accumulated on the mercury electrode at the potential of $-0.35 \mathrm{~V}$, prior to the potential scan, by stirring the solution for 1,3 and $10 \mathrm{~min}$. 
Voltammetric measurements for each accumulation time included two scans recorded in the potential range from $-0.35 \mathrm{~V}$ to $-0.9 \mathrm{~V}$. In the first scan, the reduction peak of ONP was recorded, while in the second scan on the same mercury electrode the reduction product gave a new peak at a more positive potential, which was denoted as the ONP prepeak A.

All values of the ONP peak or prepeak heights for a particular accumulation time were given as relative values normalized to the ONP peak or prepeak height in the absence of organic matter for the model system, and normalized to the accumulation time $\mathrm{t}=0$ for seawater samples and phytoplankton monocultures.

Samples were fractionated using a(n) XAD-8 resin on which organic substances were separated according to hydrophobic-hydrophilic properties (Vojvodić and Ćosović, 1996). As described in our previous paper, we measured Fraction I which is effluent solution after sorption of hydrophobic neutral and basic compounds on the XAD-8 resin at $\mathrm{pH} 8.4$, containing hydrophobic acid and hydrophilic components, and Fraction II which is effluent solutiont, after sorption of hydrophobic acid organic substances at pH 2, containing only hydrophilic substances (Gašparović et al., 1997).

Determination of the dissolved organic carbon (DOC) content in the samples was performed using the high temperature catalytic oxidation (HTCO) technique, proposed by Sugimura and Suzuki (1988). A model TOC-500 System (Shimadzu, Japan) with a highly sensitive Pt catalyst and nondispersive infrared (NDIR) detector for $\mathrm{CO}_{2}$ measurements was used.

Acidic dextrans were prepared from native dextran $\left(\mathrm{M}_{\mathrm{w}}=40.000 \mathrm{~g} / \mathrm{mol}\right)$ by carboxymethylation of hydroxyl groups on random D-glucose units, and their acidities were determined by titration of the carboxylic groups with 0.1 M NaOH in a water:acetone mixture 50:50 (v/v) (Chaubet et. al., 1995). Kappa (К)-carrageenan (Sigma) is a sulphated polysaccharide extracted from red seaweeds (Painter, 1983), and xanthan (Sigma) is a polysaccharide possessing polyelectrolyte properties, and produced by Xanthomonas campestris (Rinaudo and Milas, 1982) were used as model acidic polysaccharides which can be found in marine environment. Humic acid-Canet and fulvic acid-Canet isolated from the lagoon Canet sediment, Mediterranean, and humic acid isolated from the Raša Bay, Adriatic sea, were used.

Seawater samples were collected in the northern Adriatic Sea along the transect between the Croatian coast (Station 107) and the Po river discharge near the Italian coast (Station 101). Samples were taken with a Niskin sampler from $0.5,5,10,20$, and $30 \mathrm{~m}$, approximately monthly during a period of one year. Samples were stored in dark glass bottles at $4{ }^{\circ} \mathrm{C}$, and measured within 24 
hours. Two seawater samples were collected in the northernmost part of Adriatic sea, near Piran, Slovenia on April 3, 1995 (Sample 1) and on June 19, 1995 (Sample 2).

Phytoplankton monocultures, Phaeodactilum tricornutum as a representative of diatoms and Emiliania huxleyi as a representative of microflagelates, were in the exponential phase of growth when analyzed. Monocultures provided by the Biological Station, Piran, Slovenia, were grown in T/2 medium (Guillard and Ryther, 1962), at 293 K, under fluorescent light (I.P.R. 40 W) and a regiment of 12 hours light and 12 hours dark. Phytoplankton cells were removed from the sample by gentle filtration, under the vacuum pressure of $20 \mathrm{kPa}$.

Filtration of samples was performed through a Whatman GF/F paper filter with $0.7 \mu \mathrm{m}$ pore size.

\section{RESULTS AND DISCUSSION}

\section{Model substances}

The simple method used here for rough characterization of organic matter in seawater is based on the fact that electrochemical characteristics of the ONP peak and prepeak are strongly influenced by the properties of adsorbed organic substances on the mercury electrode, particularly the hydrophobicity and acidity of organic molecules. This was illustrated for a number of model substances, representative of organic constituents of natural seawater (Gašparović and Ćosović, 1994 and 1995). It was shown that the ONP prepeak height increased in the presence of acidic organic substances, or decreased in the presence of neutral or positively charged organic matter in comparison to that in the absence of organic matter. Ac voltammograms of ONP obtained in the absence and in the presence of $0.4 \mathrm{mg} \mathrm{dm}^{-3}$ humic acid-Raša bay for two adsorption times are presented in Fig.1. However, the extent of the increase and the concentration range of maximum effects were different for different organic layers adsorbed on the electrode.

Therefore, we used the electrochemical method with the ONP probe to study the acidity behaviour of a few model organic substances which could contribute to the acidity of marine samples. Among the chosen model organic substances, there were organics with different acidic functional groups, such as carboxylic, sulphate, and phenolic and nitrogen-containing groups contained in humic substances. Total acidities in meq/g are given in Table 1. Fig. 2. illustrates the influence of increasing concentrations of linoleic acid, marine humic and fulvic acids, melananoidin, as well as polysaccharides such as acidic dextran, $\kappa$-carraggeenan and xanthan on the ONP prepeak height. 
The obtained curves had more or less pronounced maxima. The ascending part coincided with the increasing adsorption of a particular organic substance, while at the electrode surface which was completely covered with the organic substance the prepeak height decreased more or less slowly depending on adsorption characteristics of the organic substance on the mercury electrode (Gašparović and Ćosović, 1995). Fig 2. shows that curves of more hydrophobic substances (linoleic acid, humic acid) fell in a lower concentration range and possessed more pronounced maxima with steep descending parts than is the case of hydrophilic substances (polysaccharides), where the descending part of the curve slowly decreased over a wide concentration range. Fulvic acid and melanoidin exhibited characteristics beetween the two mentioned ones, which can suggest that melanoidins can be substances which represent one step of transformation of unstable organics such as polysaccharides to recalcitrant humic organic substances in the marine environment.

The range of concentrations where the ONP prepeak increased for the investigated organic substances pointed to the following conclusions. For linoleic acid, as a representative of fatty substances, the increase of the ONP prepeak height is visible at concentrations comparable to those of real marine samples, 0.06-1.59 $\mathrm{mg} \mathrm{dm}^{-3}$ (Romankevich, 1984). Fulvic and especially humic acids caused a prepeak height increase in the range of concentrations which can be found in marine samples as well, viz. 0.06-0.6 $\mathrm{mg} \mathrm{dm}^{-3}$ expressed as DOC (Thurman, 1985). Investigated acidic polysaccharides caused an increase of the ONP prepeak at concentrations much higher than their reported values in real seawater samples, from traces to a few milligrams per liter (Romankevich, 1984).

In the experiment with four dextrans of the same weights but increased acidities, it was found that the ONP prepeak height increased with increasing acidity of dextrans (Table 2).

\section{Phytoplankton culture media}

As the largest part of organic matter in the sea derives from a biological activity, like in-situ production of planktonic organisms (Lee and Wakeham, 1988), it was interesting to examine which type of acidic organic substances are excreted by phytoplankton species. For this reason, the experiment was done with two phytoplankton monocultures, diatom $P$. tricornutum and microflagelate E. huxleyi. Recorded electrochemical characteristics of the ONP voltammetric peaks and prepeaks for the filtered phytoplankton media and the fractions are presented in Table 3.

P. tricornutum monoculture excreted acidic organic material into the medium where was grown, which showed a relative increase of the ONP prepeak height by 2.6 times in 3 min and 1.6 in 10 
min accumulation. In the hydrophilic fraction (Fraction II), there was a 3.3 times increase of the prepeak height in $10 \mathrm{~min}$ of accumulation, indicating the presence of acidic polysaccharides, which mainly constitute the hydrophilic fraction. We can suppose that these polysaccharides increase the ONP prepeak height at higher concentrations in comparison with model polysaccharides from Fig 2, which was concluded from the fact that about $60 \%$ of the starting DOC value $\left(5.0 \mathrm{mg} \mathrm{dm}^{-3}\right)$ was distributed in the hydrophilic fraction (Vojvodić et al., 1996). In the nonfractionated sample, the concentration of organic material was higher than in individual fractions, which was reflected in the time dependence of the ONP prepeak height. For the nonfractionated sample, the maximum was expected between 1 and $10 \mathrm{~min}$ of accumulation time. The hydrophilic fraction showed the ascendent part of the ONP prepeak curve, and the maximum was not reached in 10 min of accumulation. Fraction I, composed of hydrophilic and hydrophobic acid organic material, was measured diluted (1:2), and the obtained relative increase of the prepeak height of 4.2 times indicated the presence of very acidic organic substances.

In the E. huxleyi monoculture medium, the presence of acidic organic substances was observable too. The time dependence curve for the increase of the ONP prepeak height had a maximum. A relatively high increase of the prepeak height was observed at short accumulation times (2.4 and 3.1 for 1 and $3 \mathrm{~min}$, respectively), thus indicating the presence of more hydrophobic substances in the culture medium. In the hydrophilic fraction (Fraction II), prepeak heights for 1, 3 and 10 min accumulation times were small, indicating the presence of organic substances of very low acidities. Fraction I, diluted 1:2, exhibited an ONP prepeak increase of almost 5 times, and the prepeak curve was still in the ascendent part. As the hydrophilic fraction contained substances of lower acidity effects on the ONP probe, the most likely explanation for the behaviour of Fraction I would be that hydrophobic acid substances, which are components of that fraction too, were responsible for the ONP prepeak height. The shift of the ONP peak potential and the decrease of the main peak height were more pronounced in Fraction I than in Fraction II, in spite of the fact that Fraction I was measured diluted. This is in accordance with our assumption that hydrophobic acid substances are the prevalent part of organic matter of Fraction I.

\section{Seawater samples}

During the one year period, changes of the ONP prepeak height in the presence of the naturally occurring mixture of organic matter of the northern Adriatic seawater samples were followed (Fig. 3). It is visible that the biggest increases of the ONP prepeak height, indicating the presence of 
organic acidic material, were obtained for the samples collected in winter, November and February. This especially applies to Station 107, which is far away from the influence of the Po river discharge. The behaviour of the investigated model substances and comparison to the DOC values of the samples (Table 4) pointed to the conclusion that humic substances might be the dominant organic acids in these samples, due to such a big increase of the prepeak height and the fact that low temperatures and light intensities during the winter limit the phytoplankton production, which is usually higher in the warmer period of the year. Also, as high molecular weight humic and fulvic acids were found in degrading diatom debris in a laboratory experiment in a period of max. 4 months (Poutanen and Morris, 1983), it can be expected that, after the summer period of high phytoplankton productivity, freshly produced acidic organic material can be transformed by winter time and turn into dominant surface active substances in the seawater samples.

In the seawater samples from November, Station 107 (Fig. 3), relative increases of the ONP prepeak height changed from 2.9 to 4.1, from upper to deeper seawater layers, indicating increasing concentrations of humic substances with depth, which is in agreement with the previously obtained results of fractionated seawater samples (Vojvodić and Ćosović, 1996). Despite increased concentrations of humics with depth, the DOC values were very uniform along the vertical profile (Table 4).

Minimum values of the ONP prepeak height were obtained for samples collected in March, June, July, and September at Station 107. Those months coincide with the seasonal cycle for this region, which is characterized by spring and autumn diatom maxima and summer dinoflagelate succession (Revelante and Gilmartin. 1976 a and b). Thus, we could conclude that organic matter, which shows such influence on the ONP probe, is excreted by phytoplankton, and that it is of lower acidity. Dominant organic matter might involve neutral or acidic polysaccharides.

As shown in Table 4 variations of DOC values along the vertical profile are more pronounced for samples from June 1994 than for those from November 1994.

Measurements of surface active substances concentrations during a 10-year period in the same region showed that low values are more frequent in winter months while highest concentrations occur in the period from spring to early autumn (Vojvodić and Ćosović, 1996).

Two northern Adriatic samples from April '95 (sample 1) and June '95 (sample 2) were fractionated, and the ONP voltammetric characteristics were recorded for the nonfiltered and filtered samples as well as for the fractions (Table 5). For sample 1, the ONP prepeak heights of nonfiltered and filtered samples and Fractions I and II were very similar indicating that the 
hydrophilic fraction contributes mostly to the acidity of organic matter of the seawater sample from April.

As a greater shift of the ONP peak potential $(\Delta \mathrm{E})$, as indicator of hydrophobicity of organic molecules, was observed in the filtered sample than in the nonfiltered sample, it can be concluded that hydrophilic organic substances prevailed in the particulate phase of the sample too. Namely, in the presence of hydrophilic substances, the maximum peak potential shift could be around $100 \mathrm{mV}$. In contrast, a more pronounced shift up to $250 \mathrm{mV}$ is expected for hydrophobic or conditionally hydrophobic substances, which are hydrophobic at more acidic pHs (Gašparović and Ćosović, 1994). As the nonfiltered sample showed an ONP peak potential shift for 10 min accumulation of only $72 \mathrm{mV}$, and the filtered sample of $107 \mathrm{mV}$ for the same accumulation time, this indicated that hydrophilic particulate organic substances were removed from the sample during filtration, while dissolved hydrophobic substances which remained in solution were responsible for the shift of the ONP peak potential in the filtered sample. These substances were removed from the sample by sorption on the XAD-8 column, and therefore they were not present in Fraction I, which resulted in a peak potential shift of only $65 \mathrm{mV}$ for $10 \mathrm{~min}$ accumulation in this particular fraction.

In sample 2 from June, the ONP prepeak height was almost unchanged after filtration, while in Fraction I, after removing hydrophobic neutral and basic substances from the sample, the prepeak decreased. The effects upon the ONP probe obtained in Fraction I originated from both types of substances making up this fraction, i.e. hydrophobic acid and hydrophilic groups of compounds. Namely, hydrophilic Fraction II made the greater part of organic matter of the sample (DOC 1.08 $\mathrm{mg} \mathrm{dm}^{-3}$ ), and these substances caused an additional small decrease of the ONP prepeak in comparison with Fraction I. The hydrophobic acid substances, which usually show a big increase of the ONP prepeak height, represented only a small part of organic matter in this particular sample (DOC $0.37 \mathrm{mg} \mathrm{dm}^{-3}$ ).

\section{SUMMARY AND CONCLUSION}

There are different groups of organic substances, with different acidic functional groups, which contribute to the acidity of marine samples. Experiments with model surface active acidic organic substances and the ONP probe showed that all groups which contribute to the acidity of organic substances, like carboxylic, phenolic and sulphate groups, increase the ONP prepeak height. 
Changes of the prepeak height in the presence of organic substances produced by living organisms in the marine environment, such as polysaccharides, lipids and proteins are smaller than those obtained with transformed organic substances such as humic and fulvic acids and melanoidins. The highest acidities of the present organic matter, obtained as the ONP prepeak height increase, in North Adriatic seawater samples, were obtained in the winter months and in deeper seawater layers, which can be attributed to the prevalence of humic type substances in these samples. Also, humic substances can be expected after the transformation of phytoplankton produced labile organic matter and simultaneous sedimentation of the transformed organic matter.

Phytoplankton monocultures, which were richer in organic substances than the seawater samples, were investigated as well. In diatom P. tricornutum monoculture media, acidic organic substances were found mainly in the hydrophilic fraction, indicating that in natural seawater samples during the time of diatom blooms a lower ONP prepeak height increase can be expected, partly because of the potential presence of noncharged polysaccharides. In microflagelate E. huxleyi monoculture medium, hydrophobic substances were more acidic. It is in good correlation with the results of fractionated seawater samples where, in sample 1 collected in the period dominated by diatoms, acidic organic substances originated mostly from the hydrophilic fraction, while in sample 2, where microflagelates prevailed, all types of organics gave rise to the sample acidity.

\section{Acknowledgements}

The authors wish to thank J. Jozefonvicz and her assistants (CNRS, Institute Galilée, Universite Paris XIII, Villetaneuse, France) who kindly provided acidic dextrans, to M. Petrović (Faculty of Chemical Engineering and Technology, University of Zagreb, Croatia) for humic acid and C. Lee and collaborators (SUNY, Stony Brook, USA) for melanoidin sample. We thank our colleagues from the Marine Biological Station in Piran (Slovenia) for phytoplankton cultures. Financial support from the Croatian Ministry of Science, and from bilateral collaboration between France and Croatia, and the USA-Croatian grant JF-145 are gratefully acknowledged.

\section{REFERENCES}


Aiken, G.R., McKnight, D.M., Wershaw R.L. and MacCarthy, P. (eds.) (1985) Humic Substances in Soil, Sediment, and Water, Wiley-Interscience, New York.

Buffle, J. (Ed.) (1988) Complexation Reactions in Aquatic ecosystems: An Analytical Approach, Ellis Horwood, Chichester.

Chaubet, T., Champion, J., Maiga, O., Mauray, S. and Jozefonvicz, J. (1995) Synthesis and structure-anticoagulant property relationships of functionalized dextrans: CMDBS. Carbohydrate Polymers 28, 145-152.

Faguet, D. (1982) Influence des substances humiques sur les formes dissoutes et particulaires de quelques métaux (Zn, Fe, Co, Mn) dans les milieux marin et lagunaire. Ph.D. Thesis, p. 37. L'Universite de Perpignan, France.

Gašparović, B. and Ćosović, B. (1994) Electrochemical estimation of the dominant type of surface active substances in seawater samples using o-nitrophenol as a probe. Marine Chemistry 46, 179188.

Gašparović, B. and Ćosović, B. (1995) Electrochemical reduction of o-nitrophenol as a tool for the rough characterization of organic matter in seawater samples. Electroanalysis 7, 1136-1142.

Gašparović, B., Vojvodić, V. and Ćosović, B. (1997) Characterization of organic matter in fractionated seawater samples using o-nitrophenol as an electrochemical probe. Analytica Chimica Acta 338, 179-190.

Green, S.A., Morel, F.M.M. and Blough, N.V. (1992) Investigation of the electrostatic properties of humic substances by fluorescence quenching. Environmental Science and Technology 26, 294-302.

Hedges, J.I. (Ed.) (1978) The formation and clay mineral reactions of melanoidins. Geochimica et Cosmochimica Acta 42, 69-76. 
Ikeda, T., Shuto, H., Saito, T., Fukui, T. and Tomita, K. (1982) An extracellular polysaccharide produced by Zooglea Ramigera 115. European Journal of Biochemistry 123, 437-445.

Larter, S.R. and Douglas, A.G. (1980) Melanoidins-kerogen precursors and geochemical lipid sinks: a study using pyrolysis gas chromatography (PGC). Geochimica et Cosmochimica Acta 44, 2087-2095.

Lee, C. and Wakeham, S. (1988) Organic matter in seawater: biogeochemical processes. In Chemical Oceanography 9 (2nd Ed.), eds. J.P. Riley and G. Skirow, pp. 1-51. Academic Press, London.

McKnigh,t D.M., Behmel, P., Francko, D.A., Gjessing, E.T., Münster, U., Petersen, Jr. R.C., Skulberg, O.M., Steinberg, C.E.W., Tipping, E., Visser, S.A., Werner, P.W. and Wetzel, R.G. (1990) How do organic acids interact with solutes, surfaces, and organisms. In Organic Acids in Aquatic Ecosystems, eds. E.M. Perdue and E.T. Gjessing, pp. 223-243. S. Bernhard, Dahlem Konferenzen, Wiley, New York.

Novotny, F.J. and Rice, J.A. (1995) Characterization of fulvic acid by laser-desorption mass spectrometry. Environmental Science and Technology 29, 2464-2466.

Painter, T.J. (1983) Algal polysaccharides. In The Polysaccharides, Ed. G.O. Aspinal, Vol. 2., pp. 195-285. Academic Press, London.

Petrović, M. (1995) Influence of humic substances on phosphate sorption in natural systems. Ph.D. Thesis, p 58. University of Zagreb, Croatia.

Poutanen, E.-L. and Morris, R.J. (1983) A study of the high molecular weight compounds during the decomposition of a field diatom population, Estuarine Coastal and Shelf Science 17, 189-196.

Revelante, N. and Gilmartin, M. (1976a) The effects of Po river discharge on phytoplankton dynamics in the northern Adriatic sea. Marine Biology 34, 259-271. 
Revelante, N. and Gilmartin, M. (1976b) Temporal succession of phytoplankton in the northern Adriatic. Netherland Journal of Sea Research 10, 377-396.

Romankevich, E.A. (Ed.) (1984), Geochemistry of Organic Matter in the Ocean, Springer-Verlag, Berlin, Heidelberg.

Skopinstev, B.A. (1981) Decomposition of organic matter of plankton, humification and hydrolysis. In Marine Organic Chemistry, eds. E.K. Duursma and R. Dawson, pp. 125-178. Elsevier, Amsterdam.

Sugimura, Y. and Suzuki, Y. (1988) A high-temperature catalytic oxidation method for the determination of non-volatile dissolved organic carbon in seawater by direct injection of a liquid sample. Marine Chemistry 24, 105-131.

Vojvodić, V., Ćosović, B. and Mirić, V. (1994) Fractionation of surface active substances on the XAD-8 resin Part I. Mixtures of model substances. Analitica Chimica Acta 295, 73-83.

Vojvodić, V. and Ćosović, B. (1996) Fractionation of surface active substances on the XAD-8 resin: Adriatic sea samples and phytoplankton culture media. Marine Chemistry 54, 119-133.

Yumaoka, Y. (1983) Carbohydrates in humic and fulvic acids from Hiroshima Bay sediments. Marine Chemistry 13, 227-237. 


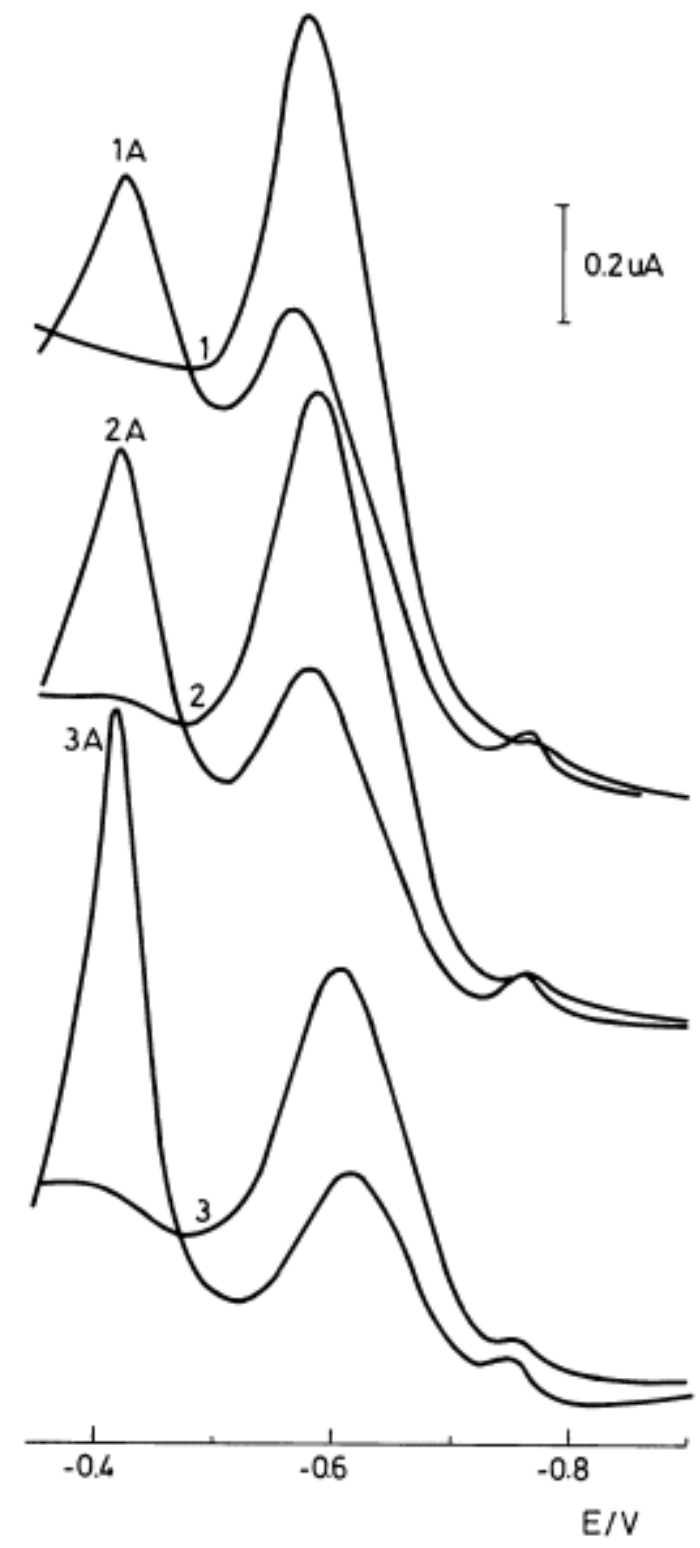

Fig. 1. Ac voltamograms (in phase) of $10-4 \mathrm{M} \mathrm{ONP}$ in $0.5 \mathrm{M} \mathrm{NaCl}, \mathrm{pH} 8.4$ in the presence of 0.4 mg dm${ }^{-3}$ humic acid-Raša bay . Accumulation times: 0 (curves 1 and 1A), 1 (curves 2 and 2A) and 3 (curves 3 and 3A) min. Curves (1), (2) and (3) first scan, and (A) second scan at the same mercury drop, recorded immediately after potential turned back to initial. 


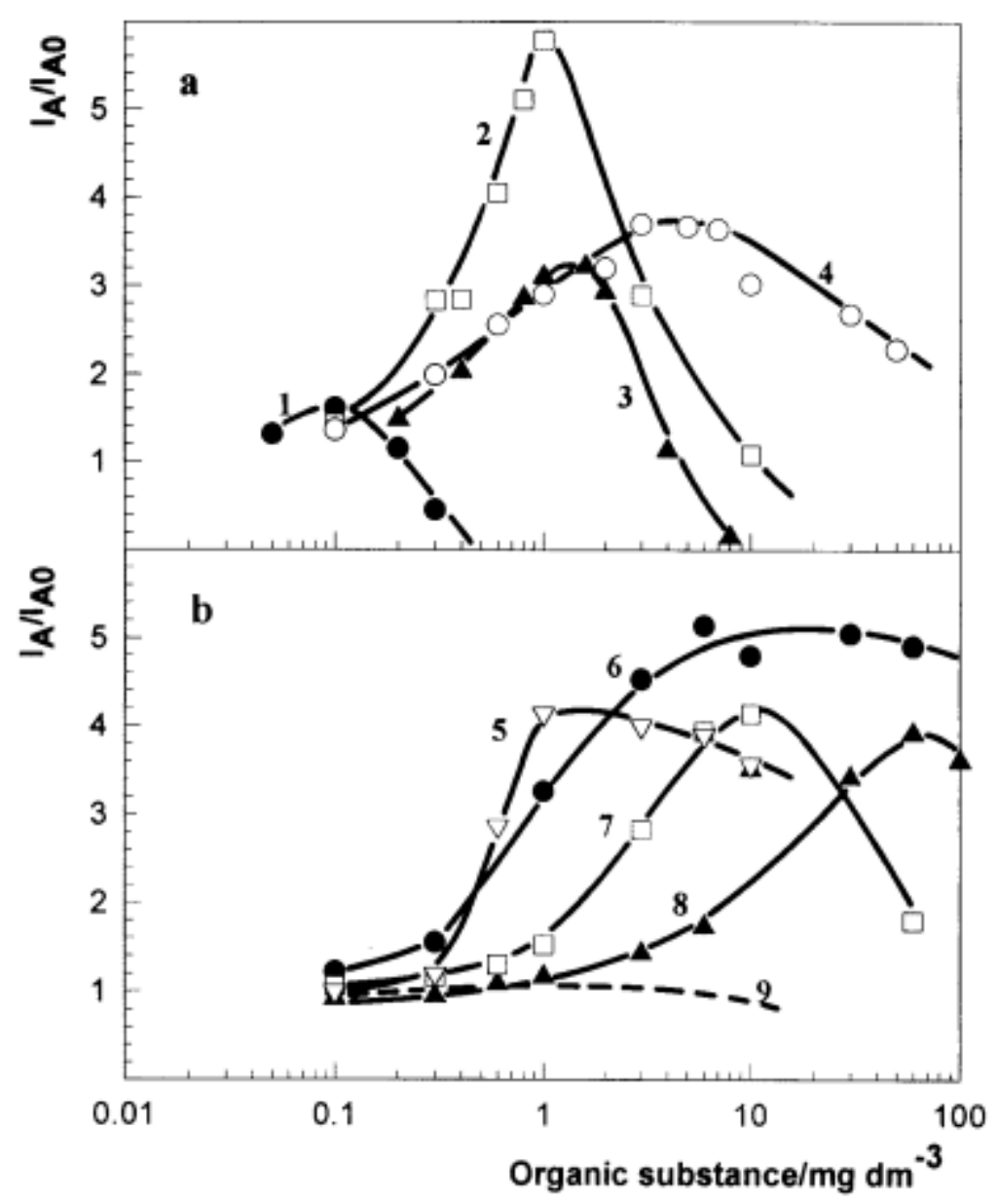

Fig. 2. Dependence of the normalized current of ONP prepeak height on the concentration of a) linoleic acid (1), humic acid-Canet (2), humic acid-Raša bay (3), fulvic acid-Canet (4), and b) acidic dextran-2 (5), melanoidin (6), א-carrageenan (7), and xanthan (8). For comparison, neutral dextran (9) is presented by dashed line. Accumulation time 3 min. 


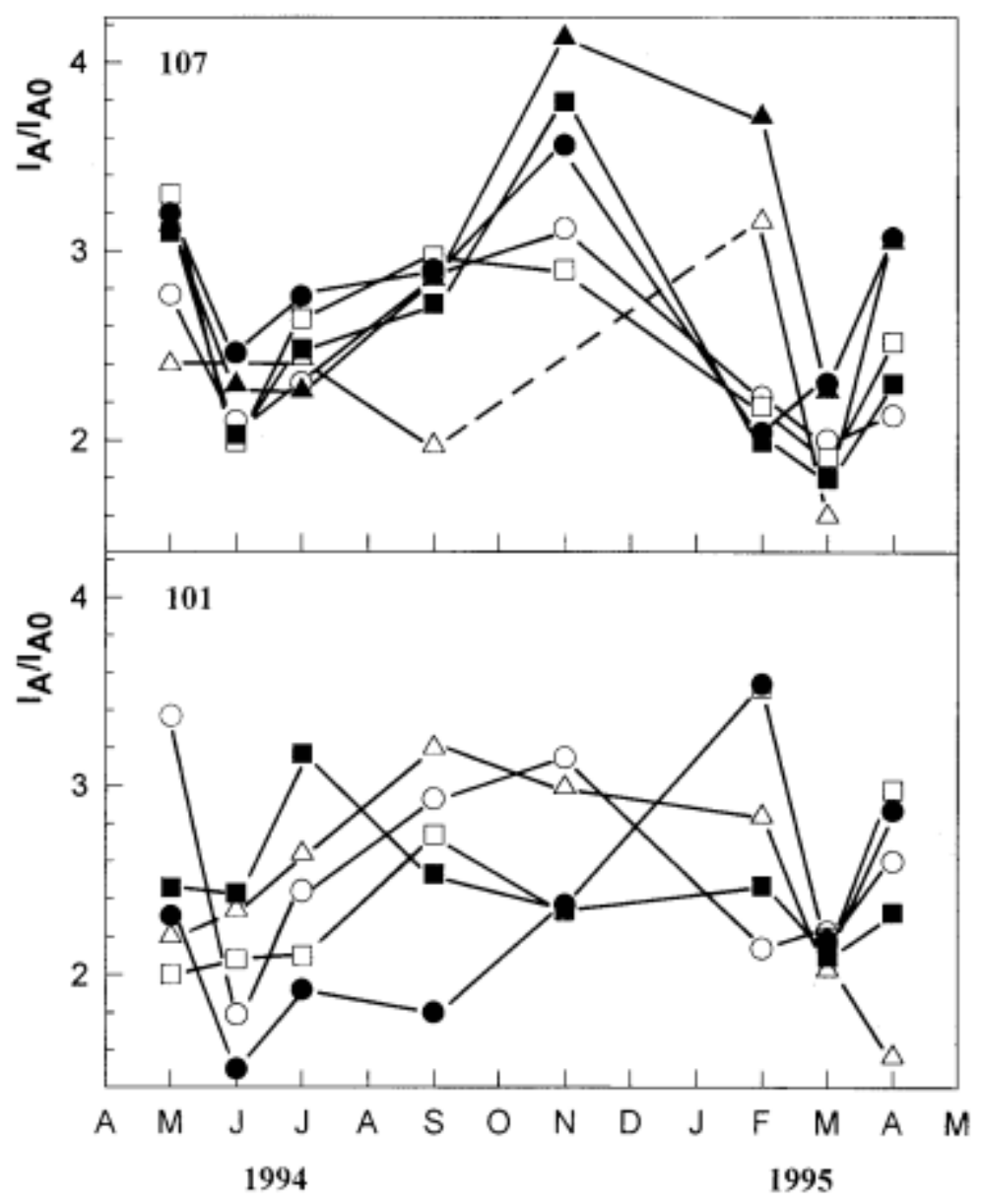

Fig. 3. Variations of ONP prepeak height in seawater samples collected in the northern Adriatic Sea

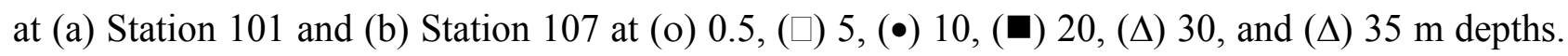
Accumulation time $3 \mathrm{~min}$. Lines are guides for eyes. 
Table 1. Acidities of model organic substances

\begin{tabular}{lc}
\hline & $\begin{array}{l}\text { Acidity } \\
\mathrm{meq} / \mathrm{g}\end{array}$ \\
\hline HA-Canet & $3.65^{\mathrm{a}}$ \\
FA-Canet & $5.82^{\mathrm{a}}$ \\
HA-Raša Bay & $4.18^{\mathrm{b}}$ \\
Acidic Dextran 1 & $1.99^{\mathrm{c}}$ \\
Acidic Dextran 2 & $2.83^{\mathrm{c}}$ \\
Acidic Dextran 3 & $3.65^{\mathrm{c}}$ \\
Acidic Dextran 4 & $3.95^{\mathrm{c}}$ \\
\hline
\end{tabular}

${ }^{a}$ Faguet, 1982

${ }^{\mathrm{b}}$ Petrović, 1995

${ }^{c}$ provided by Jozefonvicz J. (Chaubet et al., 1995)

Table 2. Maximum prepeak current of ONP normalized to ONP in the absence of organic matter for dextrans of different acidities are presented. Prepeak heights are obtained for same accumulation time (3 $\mathrm{min})$.

\begin{tabular}{lc}
\hline & $\mathrm{i}_{\mathrm{A}} / \mathrm{i}_{\mathrm{Ao}}$ \\
\hline Acidic Dextran 1 & 3.57 \\
Acidic Dextran 2 & 4.14 \\
Acidic Dextran 3 & 4.32 \\
Acidic Dextran 4 & 5.20 \\
\hline
\end{tabular}


Table 3. Electrochemical characteristics of ONP voltammetric peaks for the phytoplankton monocultures and fractions for different accumulation times (1, 3 and $10 \mathrm{~min})$

\begin{tabular}{|c|c|c|c|c|c|c|c|c|c|c|}
\hline \multirow[t]{2}{*}{ Monoculture } & \multirow{2}{*}{$\begin{array}{l}\text { DOC } \\
\left(\mathrm{mgdm}^{-3}\right)\end{array}$} & \multicolumn{3}{|c|}{$\mathrm{i}_{\mathrm{A}} / \mathrm{i}_{\mathrm{Aoo}}{ }^{\mathrm{a}}$} & \multicolumn{3}{|c|}{$\Delta \mathrm{E} / \mathrm{mV}^{\mathrm{b}}$} & \multicolumn{3}{|c|}{$\mathrm{i}_{\mathrm{p}} / \mathrm{i}_{\mathrm{p} 0}{ }^{\mathrm{c}}$} \\
\hline & & 1 & 3 & 10 & 1 & 3 & 10 & 1 & 3 & 10 \\
\hline P. Tricornutum & 5.0 & 1.7 & 2.6 & 1.6 & $\mathrm{~S}^{\mathrm{e}}$ & 70 & 103 & $\mathrm{~S}$ & 0.73 & 0.51 \\
\hline Fraction I $(1: 2)^{\mathrm{d}}$ & & 1.5 & 2.5 & 4.2 & 16 & 43 & 86 & 0.84 & 0.71 & 0.56 \\
\hline Fraction II & & 1.5 & 2.2 & 3.3 & 19 & 50 & 77 & 0.80 & 0.67 & 0.57 \\
\hline E. Huxleyi & 5.4 & 2.4 & 3.1 & 1.6 & 43 & 85 & 110 & 0.76 & 0.65 & 0.60 \\
\hline Fraction I $(1: 2)^{\mathrm{d}}$ & & 1.8 & 3.1 & 4.9 & 13 & 30 & 80 & 0.84 & 0.70 & 0.56 \\
\hline Fraction II & & 1.4 & 2.1 & 2.2 & 6 & 21 & 66 & 0.91 & 0.75 & 0.58 \\
\hline
\end{tabular}

anormalized prepeak current of ONP (second scan); $i_{A 0}$ is the prepeak current without accumulation and $i_{\mathrm{A}}$ is the prepeak current after a certain accumulation time

${ }^{b}$ shift of the peak potential of ONP voltammetric peak

${ }^{c}$ normalized peak current of ONP; $i_{p 0}$ is the peak current without accumulation and $i_{p}$ is the peak current after certain accumulation time

dilution

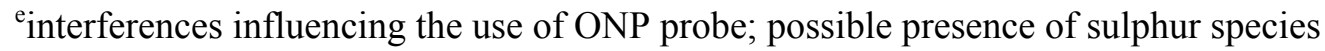

Table 4. DOC values of seawater samples from different depths at Station 107, in June 21, 1994 and November 17, 1994.

\begin{tabular}{llccccc}
\hline & Date & DOC & $\left(\mathrm{mg} \mathrm{dm}^{-3}\right)$ & & & \\
\cline { 3 - 7 } & & $0.5 \mathrm{~m}$ & $5 \mathrm{~m}$ & $10 \mathrm{~m}$ & $20 \mathrm{~m}$ & $35 \mathrm{~m}$ \\
\hline Sample 1 & June 21, 1994 & 1.25 & 0.93 & 1.83 & 0.92 & 1.01 \\
Sample 2 & November 17, 1994 & 1.53 & 1.12 & 1.23 & 1.14 & 1.14 \\
\hline
\end{tabular}


Table 5. Electrochemical characteristics of ONP voltammetric peaks for the seawater samples and fractions for different accumulation times (1, 3 and $10 \mathrm{~min})$

\begin{tabular}{|c|c|c|c|c|c|c|c|c|c|c|}
\hline \multirow[t]{2}{*}{ Sample } & \multirow{2}{*}{$\begin{array}{l}\text { DOC } \\
\left(\mathrm{mgdm}^{-3}\right)\end{array}$} & \multicolumn{3}{|c|}{$\mathrm{i}_{\mathrm{A}} / \mathrm{i}_{\mathrm{AO}^{a}}{ }^{\mathrm{a}}$} & \multicolumn{3}{|c|}{$\Delta \mathrm{E} / \mathrm{mV}^{\mathrm{b}}$} & \multicolumn{3}{|c|}{$\mathrm{i}_{\mathrm{p}} / \mathrm{i}_{\mathrm{p} 0}{ }^{\mathrm{c}}$} \\
\hline & & 1 & 3 & 10 & 1 & 3 & 10 & 1 & 3 & 10 \\
\hline \multicolumn{11}{|l|}{ Sample 1} \\
\hline$N f^{d}$ & & 1.7 & 2.4 & 3.9 & 12 & 42 & 72 & 0.85 & 0.71 & 0.58 \\
\hline $\mathrm{F}^{\mathrm{e}}$ & 1.07 & 1.6 & 2.2 & - & 16 & 54 & 107 & 0.67 & 0.44 & - \\
\hline Fraction I & 0.74 & 1.7 & 2.3 & 4.4 & 8 & 30 & 65 & 0.83 & 0.58 & 0.47 \\
\hline Fraction II & 0.48 & 1.7 & 2.4 & 3.9 & 3 & 21 & 86 & 0.90 & 0.60 & 0.53 \\
\hline \multicolumn{11}{|l|}{ Sample 2} \\
\hline$N f^{d}$ & & 3.1 & 3.4 & 3.7 & 37 & 69 & 75 & 0.68 & 0.62 & 0.48 \\
\hline $\mathrm{F}^{\mathrm{e}}$ & 1.84 & 2.5 & 3.4 & 3.6 & 34 & 57 & 84 & 0.78 & 0.72 & 0.60 \\
\hline Fraction I & 1.45 & 2.0 & 2.7 & 3.1 & 13 & 43 & 77 & 0.84 & 0.70 & 0.61 \\
\hline Fraction II & 1.08 & 2.6 & 2.8 & 2.1 & 6 & 38 & 57 & 0.73 & 0.59 & 0.57 \\
\hline
\end{tabular}

${ }^{a}$ normalized prepeak current of ONP (second scan); $i_{\mathrm{A} 0}$ is the prepeak current without accumulation and $\mathrm{i}_{\mathrm{A}}$ is the prepeak current after certain accumulation time

${ }^{b}$ shift of the peak potential of ONP voltammetric peak

cnormalized peak current of ONP; $i_{p 0}$ is the peak current at $t=0$ and $i_{p}$ is the peak current for selected accumulation time

${ }^{\mathrm{d}}$ nonfiltered sample

${ }^{\text {efiltered sample }}$ 